\title{
CADA CONTO AUMENTA UM PONTO
}

\section{O lúdico e o pedagógico orientam leitura, interpretação de texto e produção de livro de contos por alunos da quarta série}

Ao lermos Alexandre e outros heróis, contos de Graciliano Ramos', ou melhor, de Alexandre, como preferiam as crianças meus alunos da quarta série -, nos vinha um universo de idéias que nos permitiam modificar a história que havíamos acabado de ouvir, ou mesmo criar outra totalmente diferente. Criamos várias histórias e muitas delas, as mais engraçadas, povoavam nossas mentes como as histórias de fadas que ouvíamos quando crianças. Parece até que precisamos sempre ter histórias para contar e ouvir, as quais nos levem a lugares distantes ou não conhecidos.

Relembrando, agora, os contos produzidos pela classe, posso avaliar o quanto foi importante, neste projeto pedagógico, ter abandonado a vontade inicial de pedir aos alunos que produzissem muitos textos e, ao contrário, ter lido e relido vários contos do livro; ter acreditado um pouco mais nos apelos das crianças que solicitavam novas leituras.

No início o que mais intrigou a classe foi pensar na veracidade dos contos. Muitos alunos acreditavam em Alexandre e afirmavam categóricos:

“-Isso é verdade! Como história de pescador, ele só aumenta um pouco, mas aconteceu".

Na sala de aula, como leitura compartilhada, a interpretação dos contos ocorreu em diferentes situações: ou eu lia os contos para os alunos, ou um aluno lia para classe ou, ainda, montávamos uma espécie de jogral com intérpretes para cada personagem. As crianças faziam antecipações e análises prévias à leitura a partir do título, de um trecho ou de uma ilustração. Dependendo da forma que líamos o texto, as crianças os interpretavam de forma diferen-

\section{A AUTORA}

\section{Cláudia Cavalcante}

Professora de primeiro grau na rede particular de ensino, em São Paulo. te. Eram sempre mais ricas as discussões decorrentes das leituras dramatizadas. Além da discussão do conto propriamente dito, discutíamos como 

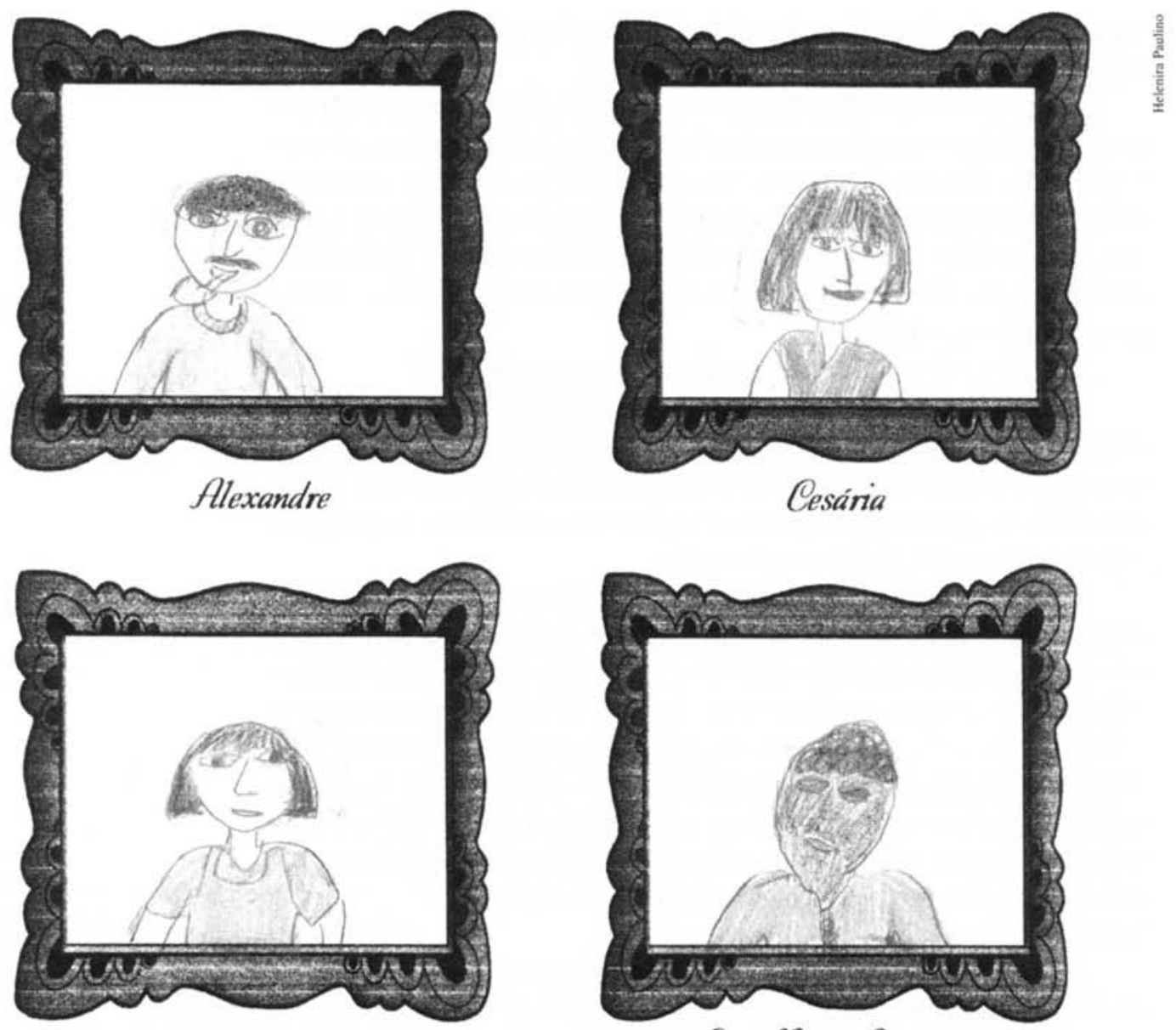

Das Dores
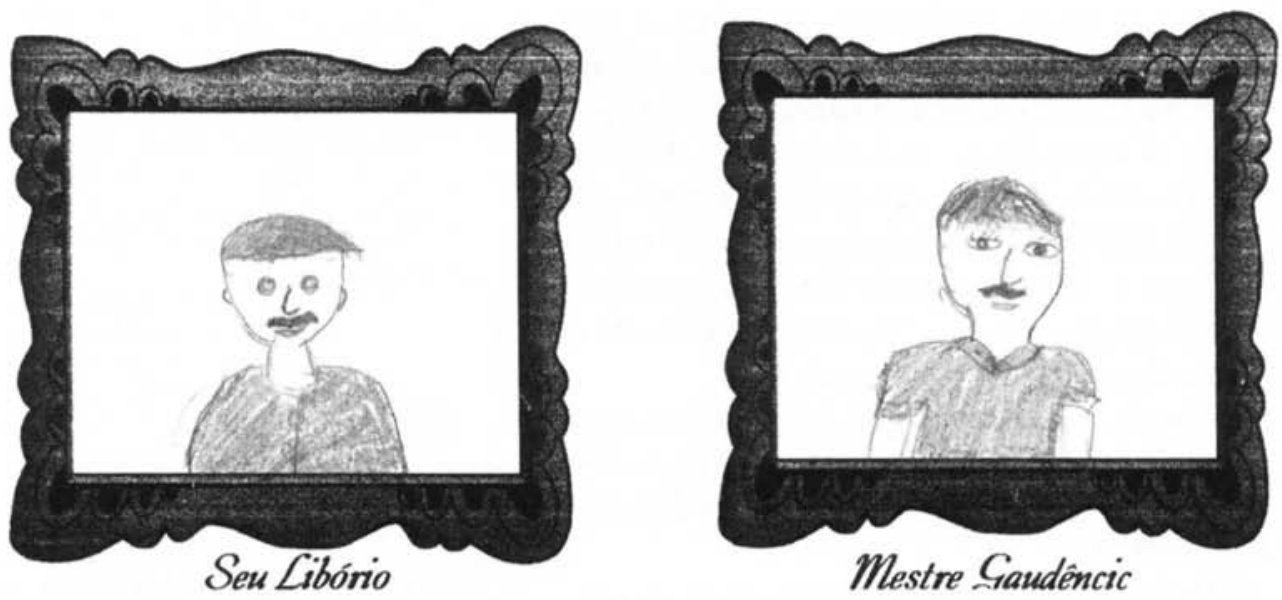

Cada criança buscou retratar o perfil dos personagens dos contos. 
tinham sido feitas as interpretações, buscando argumentos nas descrições presentes no livro.

Durante as leituras, fazíamos algumas pausas, iniciando um bate-papo bem informal no qual discutíamos inúmeros aspectos do conto lido. Conversávamos sobre o sentido de algumas palavras, primeiro tentando descobri-lo pelo contexto e, se não fosse possível, procurando seu significado no dicionário. Muitas expressões utilizadas por Graciliano também foram por nós discutidas, como por exemplo a máxima:

"Todos nós um dia embarcamos em canoa furada".

Ao longo do desenvolvimento do projeto, parávamos para anotar nossas discussões no caderno. Pedi que deixassem uma parte reservada para anotações de leitura e a subdividimos em: características de personagem, características do ambiente, linguagem, características dos contos e glossário.

Devagar, sem grandes pretensões, pedia aos alunos, em momentos diferentes, que anotassem aspectos que julgassem relevantes. Estas atividades eram realizadas em dupla ou individualmente. Para ouvir os contos ou fazer seus registros, os alunos organizavam o espaço físico da sala. Após os primeiros registros, fizemos uma roda de conversa para circular as anotações. Cada um lia suas anotações para podermos estabelecer parâmetros sobre o quê e como ressaltar. Ninguém tinha clareza do que iria acontecer na discussão.

Aproveitei este momento para desenvolver o trabalho com anotações.

Aos poucos, as crianças foram se apropriando da estrutura dos contos do livro Alexandre e outros heróis e percebendo a função de cada personagem dentro da narrativa.

Cada vez mais conseguiam antecipar o que iria acontecer até que, determinado dia, brincamos de Graciliano: cada criança inventou um final para o conto $O$ Marquês de Jaqueira, antes de ler o original. Foi muito interessante notar o quanto cada aluno se esforçava para imitar o estilo do autor, preocupando-se com as características do ambiente, dos personagens, com o vocabulário utilizado e a estrutura dos textos que compunham.

Em outra aula, propus que criassem um conto "à moda de Graciliano", porém escolhendo um ambiente que fosse familiar a eles para poder descrevê-lo melhor.

Elaborado, em dupla, o conto levou os alunos a repensar constantemente a linguagem escri-

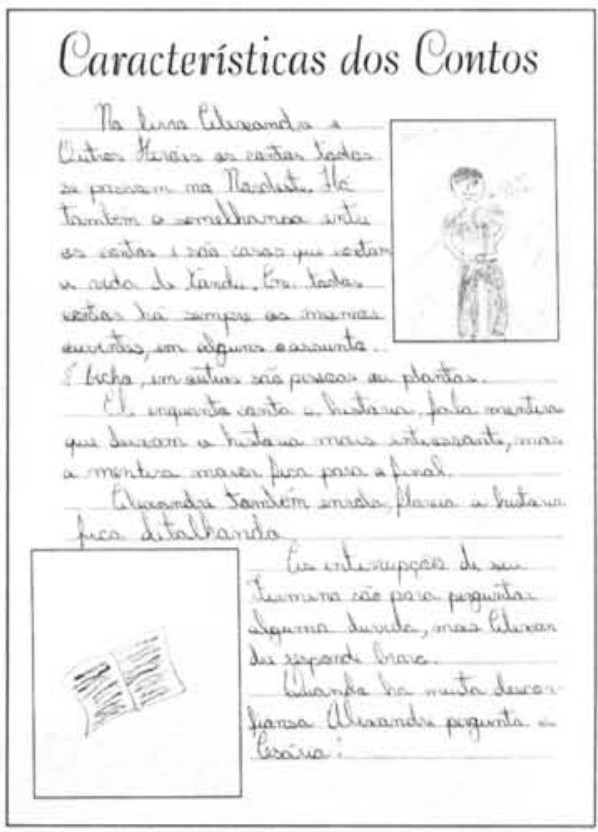

A aluna Helenira Paulino, quarta série B, escreve sobre a composição das características dos contos de Graciliano Ramos. 
ta. Em cada dupla os co-autores trocavam idéias e discutiam problemas durante todo o trabalho de produção. Isso caracterizou a atividade muito mais como situação de aprendizado sobre a língua do que uma simples atividade de produção textual na qual o aluno escreve mecanicamente.

O momento da revisão foi uma outra situação de aprendizagem. As duplas trocaram seus contos para serem lidos e analisados conforme as orientações seguintes:

Leiam o conto de seus colegas e observem se possui estrutura parecida com a dos contos de Graciliano; se os personagens mantêm suas características próprias e se o ambiente foi bem caracterizado. Caso você perceba problemas indique-os e procure apresentar mudanças para melhorá-lo.

Obs: As sugestões devem ser escritas em folha à parte para melhor orientar os colegas.

Durante a produção dos contos, notei que muitos alunos adoravam ouvir as histórias, reinventar finais, inventar um conto oralmente, mas na hora em que se deparavam com o papel e o lápis não registravam de forma satisfatória seu texto.

Todos sabemos que escrever não é uma tarefa difícil apenas para crianças, muitos adultos também se vêem em maus lençóis quando são chamados a escrever.

Muitas idéias povoam as cabeças das crianças na hora da produção escrita: a história, a descrição dos personagens, a caracterização do ambiente, o tipo de personagem, a importância do ambiente, os aspectos formais da língua (ortografia, concordância etc.). Este foi um dos motivos que me levaram a propor elaborações textuais em dupla. Esta organização garante não só um bom resultado em relação ao produto final como também em relação aos ganhos obtidos por cada criança ao trocar informações com os colegas. Uma tarefa que auxiliou bastante a produção do conto foi o momento do planejamento. Em dupla as crianças criaram oralmente a história, discutiram sobre o ambiente, personagem e trama. Com a história pronta iniciaram o processo de escrita, o que suscitou outras discussões.

Em quase todas as produções existia um destinatário ou uma finalidade explícita para o texto dos alunos. O objetivo era organizar o conhecimento adquirido durante o estudo de literatura regional do Nordeste. A forma de organização foi escolhida pela classe. Inicialmente mostrei trabalhos de anos anteriores, abri uma discussão em que cada dupla apresentou sua proposta. 
Os alunos optaram por montar um livro registrando as informações da seguinte maneira:

- introdução (feita pela professora)

- apresentação (classe)

- biografia (selecionada pela classe)

- características dos personagens

- características do ambiente

- linguagem

- glossário

- contos produzidos pela classe

Os resultados foram bastante relevantes e todos trabalharam tentando aplicar o aprendizado efetuado em sala de aula.
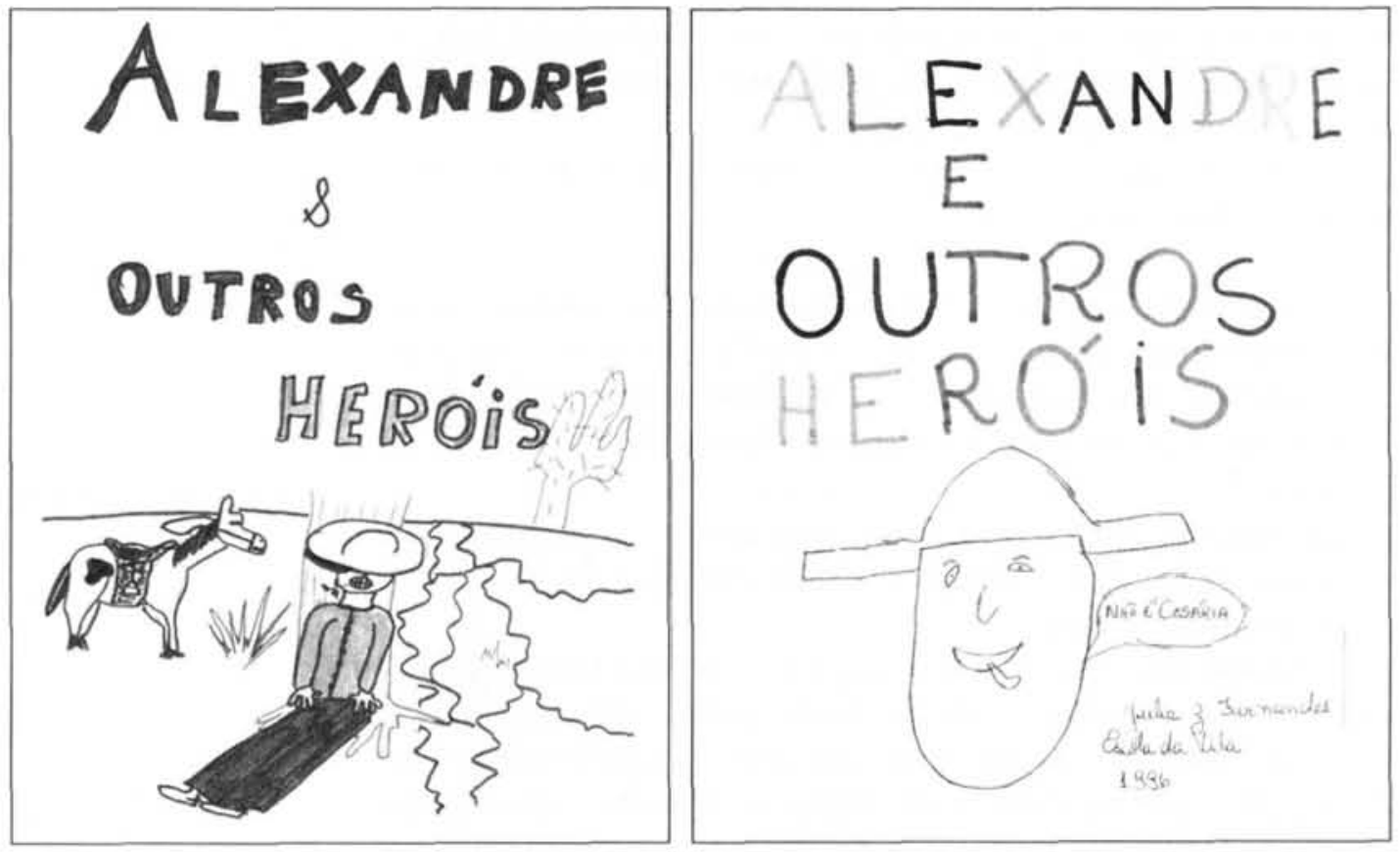

Capa dos livros produzidos pelas alunas: Júlia Z. Fernandes e Júlia Izuno Diniz.

Resumo: Professora relata experiência com atividade através da qual, partindo da leitura do livro Alexandre e outros heróis, de Graciliano Ramos, alunos da quarta série do primeiro grau analisam as caracteristicas do gênero, perfil de personagens, vocabulário e caracteristicas de composição textual e do ambiente, para depois produzirem seu próprio livro de contos.

Palavras-chave: conto, Graciliano Ramos, Alexandre e outros heróis, produção de texto, ensino de Português
Abstract: A professor gives an account of an experience in which fourth grade students, based on the reading of the tale book Alexandre e outros heróis (Alexander and others heroes), by Graciliano Ramos, analyze the characteristics of the genre, the character profiles, vocabulary and textual composition of the environment in order to then produce their own tales.

Keywords: Tale books, Graciliano Ramos, Alexandre e outros heróis (Alexander and others heroes), text production, Portuguese teaching 